\section{ANALYSIS OF GRASSROOTS INNOVATION PRACTICE TOWARDS SUSTAINABLE DEVELOPMENT IN MALAYSIA}

\author{
Fandi Ahmad Syah Amir Syah \\ Universiti Putra Malaysia \\ Khairul Aidil Azlin Abd Rahman \\ Universiti Putra Malaysia \\ Mohamad Fakri Zaky Ja'afar \\ Universiti Putra Malaysia \\ Mohd Yazid Mohd Yunos \\ Universiti Putra Malaysia
}

Corresponding Authors fandiahmad_syah@yahoo.com drkhairulazlin@upm.edu.my zakyjaafar@upm.edu.my mohdyazid@putra.upm.edu.my
Grassroots innovation is an activity that uses multiple resources or indigenous technology to create an innovation more creatively. The innovations are often utilised to improvise the community and environment. The invented product or process is created at the bottom of the pyramid due to necessities, difficulties, and challenges. Malaysia thrives to become a high income developed nation through several initiatives, such as lifelong learning and innovation. Malaysians are encouraged to undertake education programmes to enhance knowledge and skills. These grassroots activities need to be discovered as they affect income and social values. The local grassroots innovators have difficulty commercialising the innovations due to a lack of skills, knowledge, and technology. This study aimed to identify the grassroots innovations, the process in developing innovation, and complement the innovation towards commercialisation. Local innovators adapt to the new product development process as a mutual understanding and for grassroots sustainable development.

Keywords: Grassroots innovation, New product development (NPD) process, Commercialisation, Grassroots sustainable development 


\section{INTRODUCTION}

Grassroots innovation refers to the innovative product, process or service developed by grassroots innovators, usually due to necessities and challenges in life. Malaysia expects employees or human resources to be highly knowledgeable, creative and innovative in line with the government's policy. The indigenous resources and technology at the grassroots levels empower the society and country. According to the Prosperity Vision (2030), Malaysia is committed to achieving sustainable growth concurrently with fair and equitable distribution across income groups, ethnicities, regions and supply chains. The commitment aims to strengthen political stability, enhance the nation's prosperity, and ensure a united society while celebrating ethnic and cultural diversity as the nation-state's foundation.

The grassroots innovation movement seeks an innovation process that is socially inclusive towards local communities concerning the knowledge, process, and outcomes involved (Smith, Fressoli \&Thomas, 2014). Point number six stated in the 'Nine Challenges of Malaysia's Vision 2020' discusses establishing a scientific, innovative, forward-looking and progressive society. Society should be a consumer of technology and a contributor to future scientific and technological civilisation (Vision, 2020). The society in this country is expected to be more innovative by 2020 , not only as consumers of technology but also contribute to the advancement of technology used.

Grassroots innovation differs from conventional market-based innovations because grassroots innovations are driven by ideological commitment rather than profit-seeking (Seyfang \& Smith, 2007). Grassroots innovation generates sustainable economic growth, realises social innovation and exposes society to environmental responsibility. Point number eight stated in "17 Goals to Change Our World" discusses decent work and economic growth (Sustainable Development Goals (SDGs), 2015). The 17 goals to transform the world for persons with disabilities parallel to the United Nation's vision for 2030. This group of people create innovation, increase the local community income and enhance social values.

Grassroots innovation is the activity that use multiple resources or indigenous technology to create an innovation more creatively to empower the community. Hilmi (2012) stated that grassroots innovation is a collection of innovations and products, whereas the projects are implemented by those at the bottom of the pyramid and create sustainable development. Many types of products are produced by grassroots innovators, such as recyclable furniture design, low cost of housing development, agriculture products, multipurpose products and vehicles and handicrafts involving community development schemes or programmes. 
Ciftci and Walker (2017) asserted that products and innovations practised by grassroots innovators include craft, music instruments, shoes, jewellery, brassware, carpets and others. Grassroots innovation in Malaysia is one of the high impact programmes intended to empower the bottom $40 \%$ of the income pyramid (Hashim, 2012). Figure 1, shows examples of products and innovations developed by local grassroots innovators such as traditional instruments, kompang, gasing, wau and food processing equipment to be commercialised as an initiative and with support from the Malaysia Innovation Foundation or Yayasan Inovasi Malaysia (YIM).

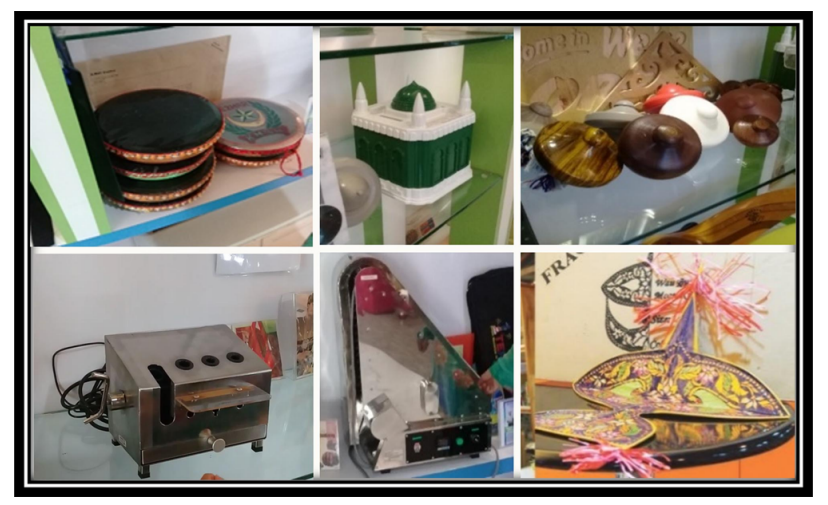

Figure 1: Examples of products and innovation created by Malaysian grassroots innovators (Malaysia Innovation Foundation Gallery, 2016).

\section{METHODOLOGY}

This study focused on the innovator's role in producing grassroots innovation to adapt to the new product development (NPD) process towards the country's sustainable development. Product commercialisation is a fundamental component to be addressed throughout the NPD process and focuses on extensive exploration of systematic literature studies on grassroots innovation practices. Data were collected from books, papers, journals, documents and other sources. This primary research and literature review is essential to identify and understand the current issues and seek information within grassroots innovation as the world moves towards a technology era.

Data collection included reviewing the attributes of local grassroots innovators, stakeholders, and supporting agencies. The data were extracted from journals and books related to past studies conducted by various researchers and reporting on issues related to grassroots innovation. In addition, data were collected through interview sessions conducted with the Malaysia Innovation Foundation or YIM, the central agency and critical player in the development of Malaysia's grassroots innovation. Researchers linked three main components, namely grassroots innovators, NPD process and commercialisation, from the data collected. According to the primary and 
secondary research, the NPD process elements were identified, and conceptual framework approach for local innovators was developed to produce innovations towards commercialisation.

\section{PROBLEMS RELATED TO GRASSROOTS INNOVATORS}

The grassroots innovators have difficulty commercialising innovations due to a lack of skills, knowledge, and technology. Grassroots innovators need to adapt to the NPD process to complement the innovation by adding value to current output and transforming existing practices. Bhaduri and Kumar (2010) defined grassroots innovators as individual innovators who often undertake innovative efforts and produce innovative products to solve localised problems and generally work outside the realm of formal organisations business firms. According to Seyfang dan Smith (2007), grassroots and niche innovations differ from mainstream and business reforms as they practise different kinds of sustainable development. Some grassroots innovators are unwilling to engage or get involved with commercial entrepreneurs (Ahmad R., 2011).

The innovation process by grassroots is still focused on traditional methods, and most innovations are not commercialised. Initiatives and support to improve grassroots innovation production are available, but these initiatives are considered new and require time to materialise. Mohamed Salleh and Mohd Daud's (2019) study in the field of grassroots innovators' sustainability in Malaysia is still in an early stage and requires more in-depth research. Figure 2, illustrates the problem faced by local grassroots innovators and the ecosystem involving different agencies.

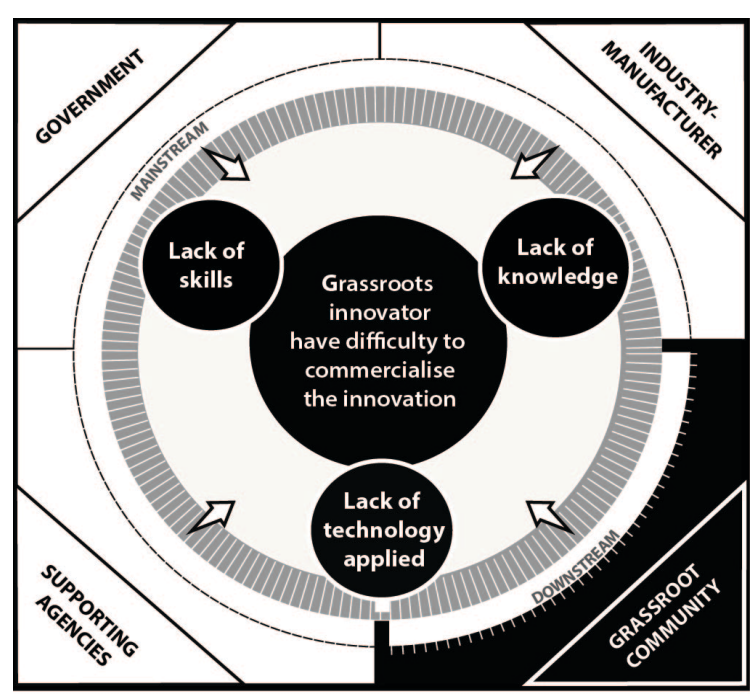

Figure 2: Problems faced by local grassroots innovator. 


\section{GRASSROOTS INNOVATORS}

Hilmi (2012) stated that humans who respond to hardship and difficulties in life could easily become accidental innovators. The profits earned are based on satisfaction from problem-solving. Grassroots innovators are unique because the majority work as farmers and never received formal education or exposed to engineering or related knowledge (Innovation Walk, 2011). In general, roots denote the lower or primary level of people in the community, whereas innovation encompasses creative ideas with added value (Innovation Walk, 2012). The grassroots includes children, youth, women, non-governmental organisations (NGOs), rural communities, and disabled individuals. The grassroots innovators are the assets in the country's sustainable development, and these innovators should be given early exposure and a platform to develop themselves.

Mohamed Salleh and Mohd Daud (2021) stated that the innovator is an individual from rural areas using their creativity of tacit knowledge and traditional skills inherited for generations to produce, enhance, and add value to existing products or services within the limitation of resources to ensure sustainability. In addition, innovators with basic knowledge in design process and management are organised and no longer rely solely on individual skills or thirds parties. According to Seyfang (2009), space is created by values and culture instead of regulation or subsidies and tend to involve ownership structures and operate in the social economy. Grassroots innovators are often relying on voluntary labour or mutual exchange.

Multilevel agency collaboration is critical in sustainable ecosystems consisting of communities, government, manufacturing industry and supporting agencies. The joint effort by Malaysian agencies is led by organisations such as the Malaysia Innovation Foundation (YIM) (2012), an NGO such as the Malaysian Association of Creativity and Innovation (MACRI) (2019), Network of Urban-Rural Innovators (NURI) (2019), a research and academic arm for innovation such as the Institute of Research Management and Innovation (IRMI), University Teknologi MARA (UiTM), (2019) and Innovation Management, University Putra Malaysia (UPM), (2019). The organisations can be pioneers in spearheading the sustainable movement of the grassroots innovator community nationwide (Mohamed Salleh \& Mohd Daud, 2019). Community and agencies should participate in the effort to develop inclusive innovation that is organised through activities and programmes, including training and workshop.

The grassroots innovation needs to be improvised comprehensively. The improvisation effort is implemented by the government and major agencies such as Malaysia Innovation Foundation (YIM) through approaches and programmes, including the Mainstreaming Grassroots Innovation (MaGRIs). This programme aims to enhance the 
development and commercialisation of grassroots innovation in Malaysia through collaboration among the government, industries and the community. In addition, this programme provides innovation development grants and building opportunities to local grassroots innovators (Article YIM, 2018). Subsequently, the intervention fulfils responsibilities and promotes innovative talents from the grassroots level. The YIM acts as a platform to find, develop and match innovation development funds with a network of more than 4,000 innovators nationwide to promote and cultivate grassroots innovations that have the potential to be commercialized while improving the well-being of the community especially the quality of life of the B40s (Yayasan Inovasi Malaysia, 2021).

The grassroots play a significant role in family institution and community and becomes a social unit that provides resources and ensures the continuity of human beings for future generations. National Population and Family Development Boards or Lembaga Penduduk dan Pembangunan Negara (LPPKN) encourage promoting and championing innovation produced by grassroots and society members. The National Family Policy (2010) aims to develop prosperous, healthy and resilient families to ensure social stability. The policy also catalyses the awareness and commitment of stakeholders, including every member of society, to achieve the desired goals. The principles applied in National Family Policy (2010) encourages the development of the family. For example, principle number four states that solid family relationships, sharing resources, and mutual responsibilities ensure family well-being. In contrast, principle number five describes knowledge and information as the basis of a prosperous family.

The innovation centres developed by the government allows the grassroots to share ideas and facilities and collaborate to create the innovations because the grassroots have different expertise or field of innovation. According to Wagner and Watch (2017), collaboration importantly underpins "open innovation" and convergence as a trend where disparate sectors and disciplines come together as a means of innovation. Innospace is a community innovation centre established by the Ministry of Science, Technology and Innovation (MOSTI) to assist local communities in developing ideas and prototypes of innovative products (MOSTI Annual Report, 2011). The Innospace contains basic facilities and a centre to provide technical and marketing advice.

The government introduced several initiatives geared towards inculcating entrepreneurial behaviour among Malaysians. According to Hilmi (2012), Malaysians are now encouraged to become entrepreneurs instead of working as employees and become innovators rather than just a user of innovation product or services. Grassroots initiatives tend to operate in civil society arenas and involve committed activists who experiment with social innovation and use greener technologies and techniques in 
contrast to the greening of mainstream business (Seyfang \&Smith, 2007). Grassroots innovators have the potential to produce products and innovations that can be marketed in the market more effectively through the intervention process. Consequently, knowledge of entrepreneurship is necessary for grassroots innovators to commercialise their products and innovations. Figure.3, displays a flow diagram on the process of grassroots innovation practices in Malaysia.

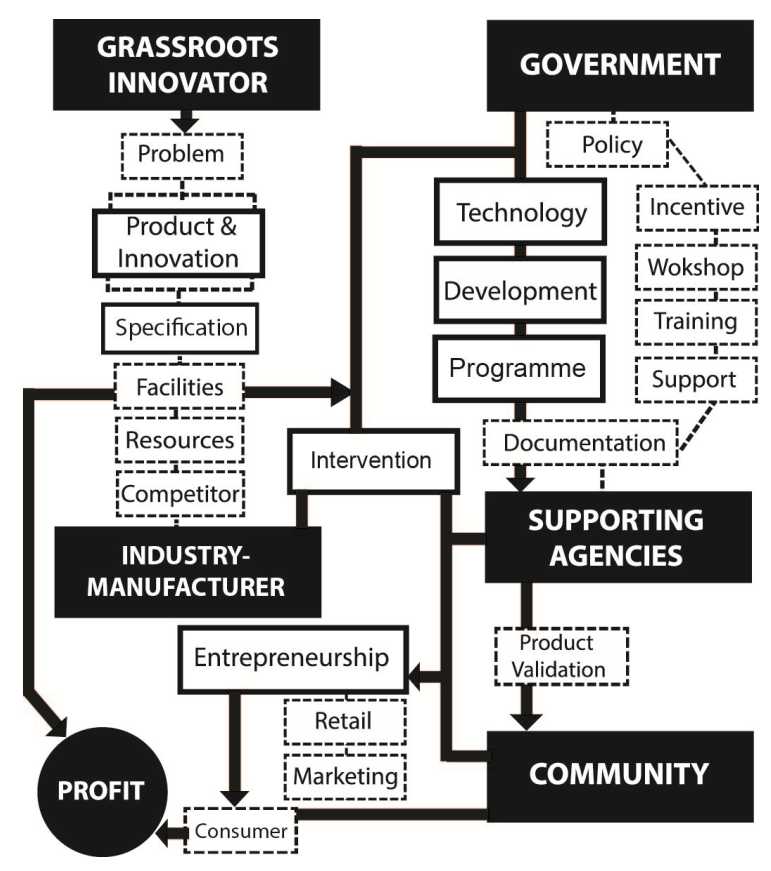

Figure 3: Flow diagram process for grassroots innovation practices in Malaysia.

\section{NEW PRODUCT DEVELOPMENT (NPD) PROCESS}

The NPD emphasises the importance of introducing new products in the market for continuous business success. Amue and Adiele (2012) determined that the NPD process is the development of original products, product improvements, product modifications, and new brands through the firm's R\&D efforts. Firms develop several activities labelled as NPD to introduce new goods (products or services) in the market. Hence, the NPD refers to the development of original products or product improvements. The critical success of a product and innovation is to fulfil market needs depending on many factors. The NPD process is guided by a new product strategy that aims to align the NPD efforts with the firm's strategic imperatives.

The NPD process is a strategy in marketing to develop a product to be produced and cater for a broader market. This method has been used in companies and industries to ensure the products and innovation produced meet users' needs and 
can be marketed widely. The NPD process consists of activities undertaken by firms when developing and launching new products. Bhuiyan (2011) stated that a new product introduced in the market evolves over a sequence of stages, beginning with an initial product concept or an idea that is evaluated, developed, tested and launched. The NPD process has to be adapted to complement the grassroots innovation because the skills are only viewed from the local perspective without applying the actual design process.

The NPD contributes to the companies' growth, influences profit performance, and plays a crucial role as a critical factor in business planning (Bhuiyan, 2011). Society expects the manufacturing industry to improve business performance continuously (Ebarefimia, 2014). All industries strive to operate and compete to expand within the dynamic environment, where NPD is a source of competitive advantage. A new product concept is a statement about anticipated product features (form or technology) that yield selected benefits relative to other products or available problem solutions (Amue \& Adiele, 2012). The grassroots are the suppliers of ideas for products, processes and services. The local idea should be commercialised for the local market since innovation entails developing a new method more appropriate for local conditions (Ahmed\& Al-Roubaie, 2012).

The Information, Communication and Technology (ICT) today is an innovation form in the Malaysian society accepted as part of new life culture. ICT use in life has several positive impacts on families and communities, explicitly facilitating information retrieval, online services, electronic commerce, and educational management. Grassroots innovators have the opportunity to use online services for businesses and seek various information. Online services, such as online payment and delivery and hosting, including online base business, are categorised as ICT based businesses and also frequently debated (Fuad, Am Bohari., \& Hin, 2011). Governments and communities need to redouble efforts to encourage and increase more use of internet-based ICT, such as e-commerce and e-business, among grassroots.

The ICT is a medium to reduce the poverty gap. Besides, ICT is a medium and tool that translate business into economic development in the current world. Science, technology, and innovation have been identified as the key elements and catalysts for economic output, social well-being, innovation, and creativity, as proven in Malaysia's ICT ecosystem (Mohamed Salleh \& Mohd Daud, 2021). Based on these rationales, grassroots need to adopt an approach to utilise ICT to empower the community and enable sustainable development. 


\section{COMMERCIALISATION}

Smith and Seyfang (2013) discussed grassroots responses by showing limitations for some extensions of current political, economic and social structures. Grassroots innovation usually involves a network of activists and organisations that produce solutions at the bottom for sustainable development, problem-solving in local situations, and giving importance to the communities' values. However, grassroots innovators have their own skills and green technologies, whereas the skills and knowledge of the community should be constantly enhanced. The development of entrepreneurship and human skills improvement have emerged as two crucial factors for a country to be a world leader in all aspects of life, such as economy, trade, military, technology, and sustainable economic and social development (Fuad, Bohari, \& Hin, 2011).

There are four critical and attention groups of technologies essential for socioeconomic transformation. According to Rahman (2013), the critical group of technologies include technologies for meeting basic needs (food, water and shelter), quality of life (e.g., education, healthcare, stabilisation of population and environmental stability), wealth creation in support of economic growth and competitiveness, and good governance in the public and private sector. Hence, improving the quality of living through technology and innovation must begin at the grassroots level.

The Research, Development and Commercialisation (RDC) system is crucial for local innovators, particularly developing local communities and delivering global goals. Rahman (2013) acknowledged that Science, Technology and Innovation (STI) formulation must include the STI and RDC system and provide for the total ecosystem to deliver the national STI agenda. Several sectorial policies may be formulated, such as for innovation, commercialisation or research funding once the inclusion is completed. The STI and RDC parallel systems show that grassroots innovators need to commercialise the inventions or the products for sustainable development to align with the national STI agenda.

Sarkar and Pansera (2017) emphasised the future of ecopreneur grassroots innovation globally. Grassroots innovation improvises economic value by combining social and environmental goals or better known as ecopreneur. Entrepreneurs in this field believe that environmentally friendly products and services will be a good combination of business opportunities and act responsibly towards the environment. Various business opportunities exist at the grassroots level for entrepreneurship and support ecopreneurs or focus on environmental 
integrity concerns. Grassroots innovators need to realise the importance of commercialisation for their products and innovation to become sustainable.

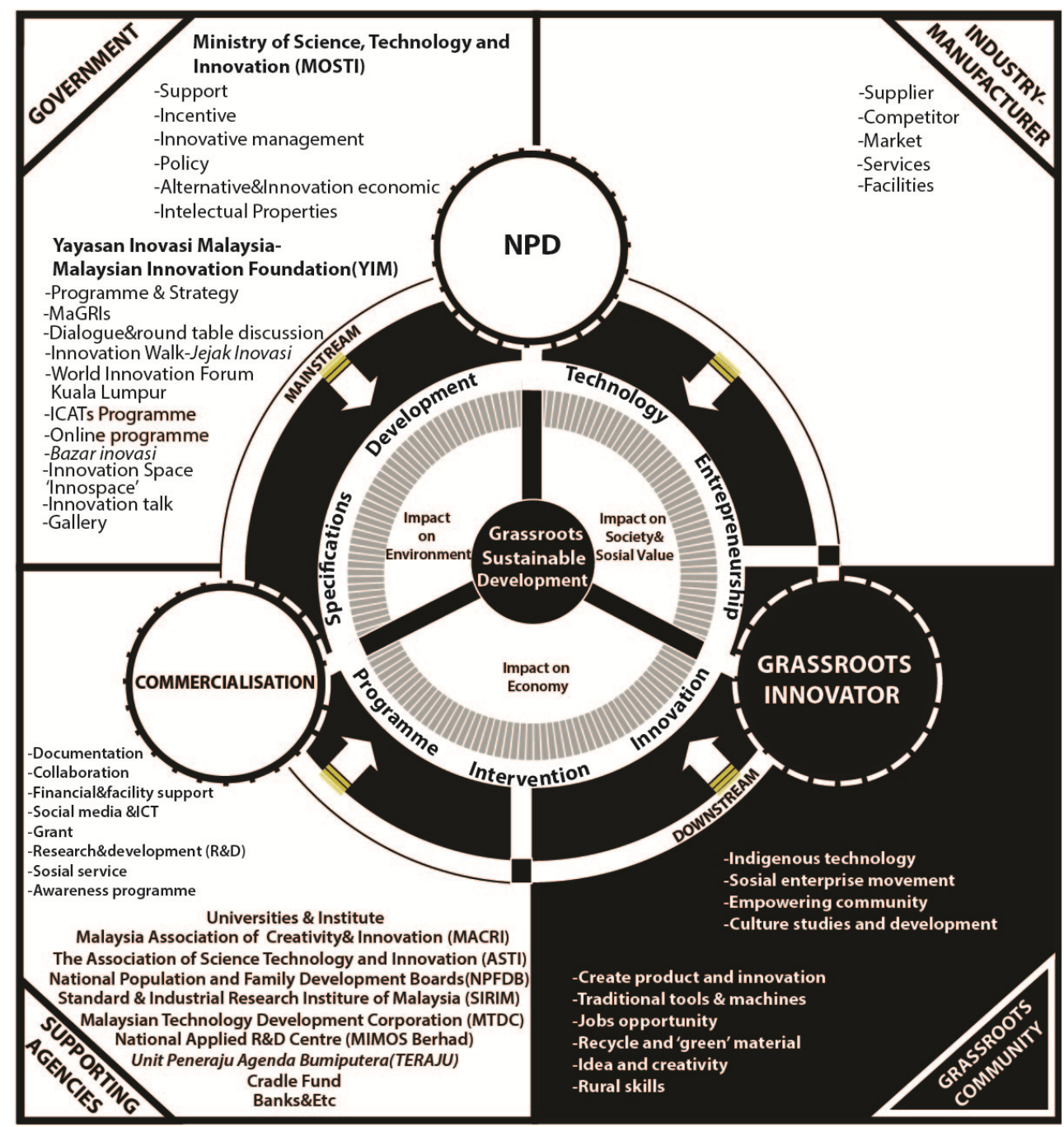

Figure 4: Conceptual framework linkages components among grassroots innovators in Malaysia and the NPD process towards commercialisation.

Figure 4, illustrates the conceptual framework with linkages between components of grassroots innovator, NPD process and commercialisation. Hence, the seven elements are the keywords affecting grassroots innovators on the NPD process, namely innovation, intervention, programme, specifications, development, technology and entrepreneurship. These elements are valuable indicators of grassroots sustainable development. 


\section{CONCLUSION}

In conclusion, the elements of the NPD process in this study are closely related to the understanding of grassroots innovators attributes. They have the potentials to encourage improvement in product commercialisation. This study critically highlights the significance of the NPD process to determine the perfect balance between the innovators' role and the potential of product commercialisation. Local innovators and authorities should work together effectively and ensure that the innovations fulfil the requirements and specifications of market standards in producing products and innovations that meet consumers' needs. The theory of the NPD process demonstrates the balance between the grassroots innovation production process through broad business linkages. Sustainable grassroots development creates meaningful job opportunities, results in grassroots stable development, maintains local values, leads to a self-standing society, and creates high life quality within the environment.

\section{REFERENCES}

1. Adrian Smith \& Gill Seyfang (2013). Constructing grassroots innovations for sustainability. Global Environmental Change, 23, 827-829.

2. Ahmed, A., \& Al-Roubaie, A. (2012). Building a knowledge-based economy in the Muslim world: The critical role of innovation and technological learning. World Journal of Science, Technology and Sustainable Development, 9(2), 76-98.

3. Amue, G.J. \& Kenneth C. Adiele (2012). New Product Development and Consumer Innovative Behaviour: An Empirical Validation Study. European Journal of Business and Social Sciences, Vol. 1, No. 6, pp 97-109, October 2012.

4. Andrian Smith, Mariano Fressoli \& Hernan Thomas (2014), Grassroots Innovation Movements: Challenges and Contributions. Journal of Cleaner Production, Volume 63 (2014) 114-124.

5. Ahmad, R (2013, August 2011). Menjejak Inovasi Akar Umbi. Utusan Malaysia.

6. (Article YIM, 2018). Yim Magris, 23 April 2019. Retrieved April 28, 2019, from http://magris.innomap.my/.

7. Bhaduri, S., \& Kumar, H. (2010). Extrinsic and intrinsic motivations to innovate: tracing the motivation of 'grassroot' innovators in India. Mind \& Society, 10(1), 2755.

8. Ebarefimia. U.S, (2014) New product development process and its impact on business performance in Nigeria. The Business \& Management Review, Volume 4 Number 4.

9. Gill Seyfang \& Andrian Smith, (2007), Grassroots innovation for Sustainable Development: Towards a New Research and Policy Agenda. Environmental Politics, Vol. 16, No 4,584-603, August 2007.

10. Hashim, H. (2012, 3 September 2012). Inclusive entrepreneurship for the rakyat, New Straits Times. 
11. Hazal Gumus Ciftci \& Stuart Walker (2017). Design for Grassroots Production in Eastern Turkey through the Revival of Traditional Handicraft. Design for next 12th EAD Conference Sapienza University of Rome-12-14 April 2017.

12. Innovation Walk (2011), Malaysia Innovation Foundation-Yayasan Inovasi Malaysia (YIM) \& Ministry of Science, Technology and Innovation.

13. Innovation Walk (2012), Malaysia Innovation Foundation-Yayasan Inovasi Malaysia (YIM) \& Ministry of Science, Technology and Innovation.

14. Julie Wagner and Dan Watch, (2017). Innovation Spaces: The New Design of Work, The Anne T. and Robert M. Bass Initiative on Innovation and Place making.

15. Mohd Faiz Hilmi (2012). Grassroots Innovation from the Bottom of the Pyramid. Universiti Sains, Malaysia. Current Opinion in Creativity, Innovation and Entrepreneurship Volume 1, Issue 2.

16. (MOSTI Annual Report, 2011) Minister of Science, Technology and InnovationMOSTI, 2011.

17. Nadia Bhuiyan (2011). A Framework for Successful New Product Development. Concordia University (CANADA) JIEM Journal of industrial engineering and management. 2011 - 4(4):746-770.

18. (National Family Policy, 2010). National Population and Family Development Board (LPPKN)-Ministry of Women, Family and Community Development (2010).

19. Nurwahida Fuad, Abdul Manaf Bohari \& Dr Cheng Wei Hin (2011), An

Exploratory Study on Socio-Economic Status of Malay Women Entrepreneurs in Penang: A Case of ICT-based Business, Jurnal Intelek 6(2).

20. Omar Abdul Rahman (2013). The Essential of Science, Technology and Innovation Policy. Academy of Science Malaysia.

21. (Prosperity Vision 2030, 2019), Restructuring Malaysia Development Priorities, Ministry of Economic Affairs, 2019.

22. Mohamed Salleh,S\& Mohd Daud, N, (2019). Probing the Influence of internet things (IOT) Usage on the Grassroots innovators' Sustainability: A Malaysian Perspective. International Journal of Innovation, Creativity and Change. Volume 7, Issues 4, 2019.

23. Mohamed Salleh,S\& Mohd Daud, N,(2021). A New Model of the Framework for the influence of the Internet of Things (IOT) Usage on the grassroots innovators' sustainability. ASM Science Journal, volume 14, 2021.

24. Soumodip Sarkar \& Mario Pansera (2017). Sustainability-driven innovation at the bottom: Insights from grassroots ecopreneurs. Technological Forecasting \& Social Change, 114, 327-338.

25. Sustainable Development Goals (SDGs), (2015). Department of Economic and Social Affairs, United Nation.Retrieved April 28, 2019,from https://www.un.org/sustainabledevelopment/ 
26. (Vision 2020), Malaysia As A Fully Developed Country - One Definition, 23 April, 2019, Retrieved April 28, 2019, from

http://www.wawasan2020.com/vision/p2.html

27. Yayasan Inovasi Malaysia (YIM), 2021. Yayasan Inovasi Malaysia Retrieved April 13,2021, https://www.yim.my/en/about/. 